\title{
Changing patterns of AIDS: impact on the indications and diagnostic yield of bone marrow biopsies
}

\begin{abstract}
After the advent of HAART, the clinical course of HIV infection has dramatically improved. Therefore, it seems appropriate to reevaluate the performance of bone marrow biopsy (BMB) as a diagnostic tool. The aim of the present study was to compare the reasons for performing a BMB and its diagnostic yield in HIV-patients before and after HAART. A total of 165 BMB specimens obtained from HIV-infected patients receiving care at the Hospital of Universidade Federal do Rio de Janeiro in two different periods (1986-1994 and 1999-2004) were analysed. The main reason for BMB examination in the first period was fever $(88 \%)$, which decreased in the second period $(57 \%, \mathrm{p}<0.0001)$, when cytopenia $(51 \%)$ was the leading reason for $\mathrm{BMB}$, whereas in the first period it accounted for only $30 \%(\mathrm{p}=0.008)$. A definitive diagnosis (infection, granulomas or lymphomas) was obtained in $28 \%$ of patients in the first period and in $19 \%$ during the second period $(\mathrm{p}=0.20)$. The diagnosis turned out as infections decreased from $16 \%$ in period 1 to $2 \%$ in period 2 ( $p=0.003$ ). Despite the the limitations in the evaluation of fever, the use of $\mathrm{BMB}$ must be considered on an individual basis, whenever less invasive alternatives have been exhausted, and should be complemented by a bone marrow aspiration for microbiological studies.
\end{abstract}

Keywords: bone marrow biopsy, HIV, HAART.

[Braz J Infect Dis 2010;14(4):419-421] @Elsevier Editora Ltda.

\section{INTRODUCTION}

The role of bone marrow biopsy (BMB) as a diagnostic tool in human immunodeficiency virus (HIV) infection remains controversial. In the early days of the epidemic, many published studies evaluated the role of $\mathrm{BMB}$, especially to elucidate persistent fever, secondary infections, cytopenias, and to stage malignancy. ${ }^{1-7}$ After the advent of highly active antiretroviral therapy (HAART), the clinical course of HIV infection has dramatically improved. ${ }^{8}$ As the clinical spectrum of this disease has changed, it is appropriate to reevaluate the performance of BMB as a diagnostic tool in the HAART scenario. ${ }^{9-11}$ The aim of the present study was to compare the diagnostic yield of BMB in HIV infected patients before and after HAART introduction.

\section{MATERIAL AND METHODS}

All consecutive BMB specimens obtained from HIV-infected patients at the Hospital of Universidade Federal do Rio de Janeiro in two different periods were retrospectively analysed. Patients in group 1 had their BMB done from November
1986 to April 1994, before the introduction of HAART in Brazil. Patients in group 2 had undergone a BMB from January 1999 to May 2004, and were on HAART for at least three months. HIV infection was confirmed in all patients according to national guidelines. The institutional review board approved the study.

BMB samples were formalin fixed, decalcified and embedded in paraffin. Sections were cut at $5 \mu \mathrm{m}$ and the following stains were routinely applied: Hematoxylin-eosin (HE), Ziehl-Neelsen (ZN) for the presence of acid-fast bacilli, and periodic acid-Schiff (PAS) and Grocott's methenamine silver (GMS) for the diagnosis of fungal infection. Each specimen was evaluated for overall cellularity, relative proportion of plasma cells, eosinophils, and for the presence of iron, dysplastic changes, abnormal localization of immature precursors (ALIP), serous degeneration, lymphoid nodules, granulomas and neoplasia. Bone marrow cellularity was defined as normocellular (40-60\%), hypocellular $(<40 \%)$ and hypercellu$\operatorname{lar}(>60 \%)$. Plasmacytosis and eosinophilia were defined as the presence of $5 \%$ or more of plasma cells or eosinophils, respectively.
Authors

José Carlos Morais, MD

Marcel Machado, MD

Irene Biasoli, $\mathrm{MD}^{2}$

Paulo Feijó Barroso, $\mathrm{PhD}^{3}$

Cristiane Milito $^{1}$

Nelson Spector, MD²

${ }^{1}$ Pathology Services*

${ }^{2}$ Hematology Services ${ }^{*}$

${ }^{3}$ Infectious Diseases

Services*

^Hospital Universitário da Universidade Federal do Rio de Janeiro, Brazil.
Submitted on: 03/04/2010 Approved on: 03/27/2010

Correspondence to: José Carlos Morais Estrada Engenho do Mato, 900, casa 03 Niterói - Rio de Janeiro - Brazil

CEP: 24.346-040 Phone: +55-21-26095990 Fax: +55-21-25622283

E-mail:

j.com@terra.com.br

This study was supported by the Conselho Nacional de Desenvolvimento

Científico e Tecnológico - CNPq and by the Fundação de Amparo à Pesquisa do Estado do Rio de Janeiro - Faperj. 
Baseline demographic and clinical characteristics retrieved from the patient record were age at the time of $\mathrm{BMB}$, sex, stage according to the WHO staging system, ${ }^{12}$ blood cell counts, clinical reason for BMB examination, and CD4 counts. CD4 counts were not available before 1994.

Categorical variables were compared with the chi-square test or Fischer's exact test, as appropriate. A p-value of $<0.05$ was considered statistically significant. The SPSS software, (Chicago, IL, US) was used to analyze the data.

\section{RESULTS}

A total of 165 BMB samples were available for analysis: 102 from group 1 and 63 from group 2. The median age was 36 (11-67) years, and was not statistically different among the two groups ( 35 and 38 years, respectively). The proportion of females increased in group $2(15 \%$ versus $32 \%, p=0.01)$. The majority of the patients in both groups presented with stage 4 disease ( $77 \%$ in group 1 and $87 \%$ in group 2 ). BMB examination was mainly indicated in group 1 was the evaluation of fever $(90 / 102,88 \%)$, and this indication significantly decreased in group $2(35 / 63$, $57 \%, \mathrm{p}<0.0001)$. Conversely, the main reason for BMB in group 2 was the presence of cytopenias $(32 / 63,51 \%)$, significantly more often than had been observed in group $1(30 / 102$, $30 \%, \mathrm{p}=0.008$ ). The third most common reason for BMB was the staging and/or investigation of lymphomas. In the first period, it accounted for 18\% (18/102) of all indications, and 27\% $(17 / 63)$ in the second period $(\mathrm{p}=0.17)$.
No differences in bone marrow histopathological features were observed between the two groups, except for the more frequent finding of a hypercellular bone marrow in group $2(18 \%$ versus $38 \%, p=0.015)$. Overall, the main histopathological findings were the presence of serous degeneration (90\%), ALIPs (21\%), lymphoid nodules (12\%), plasmacytosis (22\%), eosinophilia (30\%), megakaryocytic dysplasia (85\%), and iron deposits (58\%).

The final diagnosis of the bone marrow examination was classified into four categories: infections, granulomas, lymphomas, and others (including myelodysplasia). A definitive diagnosis either of infection, granulomas, or lymphomas was obtained in $29(28 \%)$ patients in group 1 and in $12(19 \%)$ patients in group $2(\mathrm{p}=0.20)$. However, $\mathrm{BMB}$ disclosing an infectious diagnosis decreased from $16 \%$ $(16 / 102)$ in group 1 to $2 \%(1 / 63)$ in group $2(\mathrm{p}=0.003)$ (Table 1). Patients who had undergone a BMB for the evaluation of fever, a diagnosis of infection was obtained in $25 / 102(25.5 \%)$ in group 1 , but in only $5 / 63(7.9 \%)$ patients in group $2(\mathrm{p}=0.007)$.

CD4 cell counts were available for $55 / 63$ patients $(87 \%)$ in group 2. Lower CD4 counts $(<200$ cells $/ \mu \mathrm{L})$ were observed in 39 patients $(71 \%)$. No differences were found between patients with lower and higher CD4 counts, in group 2, regarding the diagnostic yield of the BMB (20\% versus $12 \%$, $\mathrm{p}=0.7)$.

Table 1. Final diagnosis of bone marrow involvement according to the use of highly active antiretroviral therapy (HAART)

\begin{tabular}{lcccc}
\hline & $\mathbf{n}=\mathbf{1 6 5}$ & $\begin{array}{c}\text { Group 1 } \\
\text { Pre-HAART } \\
\mathbf{n = 1 0 2}\end{array}$ & $\begin{array}{c}\text { Group 2 } \\
\text { HAART } \\
\mathbf{n}=\mathbf{6 3}\end{array}$ & p-value \\
\hline $\begin{array}{l}\text { Main indications* } \\
\text { Fever }\end{array}$ & 125 & $90(88 \%)$ & $35(57 \%)$ & 0.0001 \\
\hline Cytopenia & 62 & $30(30 \%)$ & $32(51 \%)$ & 0.008 \\
\hline Lymphoma & 35 & $18(18 \%)$ & $17(27 \%)$ & 0.17 \\
\hline Infections & $17(11 \%)$ & $16(16 \%)$ & $1(2 \%)$ & 0.003 \\
$\quad$ Tuberculosis & $7(4 \%)$ & $6(6 \%)$ & $1(2 \%)$ & - \\
Atypical mycobacteriosis & $3(2 \%)$ & $3(3 \%)$ & - & - \\
Hystoplasmosis & $6(4 \%)$ & $6(6 \%)$ & - & - \\
$\quad$ Cryptococcosis & $1(0.5 \%)$ & $1(1 \%)$ & - & - \\
\hline Granuloma & $16(9 \%)$ & $10(10 \%)$ & $5(9 \%)$ & - \\
\hline Lymphomas & $8(7 \%)$ & $3(3 \%)$ & $3(5 \%)$ & 0.28 \\
Hodgkin & $4(3 \%)$ & $1(1 \%)$ & $2(3 \%)$ & - \\
$\quad$ Non-Hodgkin & $4(4 \%)$ & $2(2 \%)$ & $51(81 \%)$ & - \\
\hline Others & $124(75 \%)$ & $73(71 \%)$ & $42(67 \%)$ & 0.32 \\
$\quad$ Dysplasia & $101(61 \%)$ & $59(58 \%)$ & - & - \\
Hipoplasia & $6(4 \%)$ & $6(6 \%)$ & $9(15 \%)$ & 0.18 \\
Normal & $17(10 \%)$ & $8(8 \%)$ & - & - \\
\hline
\end{tabular}

*More than one indication could be present. 


\section{DISCUSSION}

Bone marrow biopsy has been largely used as a diagnostic tool in AIDS patients from the onset of the epidemic. Since the introduction of HAART, there have been substantial changes in epidemiological and clinical aspects of the epidemic. It is therefore appropriate to evaluate the impact of these changes on the indications and diagnostic yield of BMB in AIDS patients.

A comparison of the indications and results of $\mathrm{BMB}$ in patients treated before and after the introduction of HAART was performed. Some interesting findings emerged from this analysis: (1) The indication of BMB for evaluation of fever has decreased from $88 \%$ to $57 \%$; and (2) a sharp decrease in the diagnosis of infections through $\mathrm{BMB}$ was observed, especially when $\mathrm{BMB}$ was performed for fever evaluation.

These findings most likely reflect the reduction in the incidence of opportunistic infections brought about by HAART, and also by the introduction of effective prophylactic measures. Moreover, the availability of less invasive medical procedures, such as imaging studies and specific laboratory tests, probably contributed to the lesser use of $\mathrm{BMB}$ in patients with fever.

On the other hand, no difference was observed regarding the overall diagnostic yield of BMB in the two periods, a finding in line with previous observations. ${ }^{9}$ Also, no differences regarding the histological features in samples of BMB between the two periods were found.

Currently, the overall diagnostic yield of BMB in AIDS patients was $19 \%$. Despite the somewhat limited yield in the evaluation of fever, the use of BMB must be considered on an individual basis whenever less invasive alternatives have been exhausted, and should be complemented by a bone marrow aspiration for microbiological studies.

\section{REFERENCES}

1. Castella A, Croxson TS, Mildvan D et al. The bone marrow in AIDS. A histologic, hematologic, and microbiologic study. Am J Clin Pathol 1985; 84: 425-32.

2. Delacretaz F, Perey L, Schmidt PM et al. Histopathology of bone marrow in human immunodeficiency virus infection. Virchows Arch A Pathol Anat Histopathol 1987; 411:543-51.

3. Gluckman RJ, Rosner F, Guarneri JJ. The diagnostic utility of bone marrow aspiration and biopsy in patients with acquired immunodeficiency syndrome. J Natl Med Assoc 1989; 81:119-25.

4. Osborne BM, Guarda LA, Butler JJ. Bone marrow biopsies in patients with the acquired immunodeficiency syndrome. Hum Pathol 1984; 15:1048-53.

5. Seneviratne L, Espina BM, Nathwani BN et al. Clinical, immunologic, and pathologic correlates of bone marrow involvement in 291 patients with acquired immunodeficiency syndrome-related lymphoma. Blood 2001; 98:2358-63.

6. Santos ES, Raez LE, Eckardt P et al. The utility of a bone marrow biopsy in diagnosing the source of fever of unknown origin in patients with AIDS. J Acquir Immune Defic Syndr 2004; 37:1599-603.

7. Marques MB, Waites KB, Jaye DL et al. Histologic examination of bone marrow core biopsy specimens has limited value in the diagnosis of mycobacterial and fungal infections in patients with the acquired immunodeficiency syndrome. Ann Diagn Pathol 2000; 4:1-6.

8. Kaplan JE, Hanson D, Dworkin MS et al. Epidemiology of human immunodeficiency virus-associated opportunistic infections in the United States in the era of highly active antiretroviral therapy. Clin Infect Dis 2000; 30(Suppl 1):S5-14.

9. Llewelyn MJ, Noursedeghi M, Dogan A et al. Diagnostic utility of bone marrow sampling in HIV-infected patients since the advent of highly active antiretroviral therapy. Int J STD AIDS 2005; 16:686-90.

10. Diamond C, Taylor TH, Aboumrad T, Anton-Culver H. Changes in acquired immunodeficiency syndrome-related non-Hodgkin lymphoma in the era of highly active antiretroviral therapy: incidence, presentation, treatment, and survival. Cancer 2006; 106:128-35.

11. Tanaka PY, Hadad DJ, Barletti SC et al. Bone marrow biopsy in the diagnoses of infectious and non-infectious causes in patients with advanced HIV infection. J Infect 2007; 54:362-6.

12. World Health Organization. Interim WHO Clinical staging of HIV/AIDS and HIV/AIDS case definitions for surveillance. WKL Epidemiol Rec 1990; 65:221-8. 